\title{
Plano de Preservação Digital da VideoSaúde: estratégias para a gestão de documentos audiovisuais
}

\author{
VideoSaúde Digital Preservation Plan: strategies for the management of \\ audiovisual documents
}

\section{Plan de Preservación Digital VideoSaúde: estrategias para la gestión de documentos audiovisuales}

\author{
Marco Dreer Buarque ${ }^{1, a}$ \\ marco.dreer@gmail.com | https://orcid.org/oooo-0002-3108-6527 \\ João Guilherme Nogueira Machado,b \\ guilherme.machado@icict.fiocruz.br | https://orcid.org/0000-0002-9997-5873
}

Eliane Batista Pontes ${ }^{2, c}$

eliane.pontes@icict.fiocruz.br | https://orcid.org/0000-0002-4594-9987

\footnotetext{
${ }^{1}$ Fundação Oswaldo Cruz, Casa de Oswaldo Cruz. Rio de Janeiro, RJ, Brasil. RJ, Brasil.

a Mestrado em Bens Culturais e Projetos Sociais pela Fundação Getúlio Vargas.

b Especialização em Informação Científica e Tecnológica em Saúde pela Fundação Oswaldo Cruz.
}

2 Fundação Oswaldo Cruz, Instituto de Comunicação e Informação Científica e Tecnológica em Saúde. Rio de Janeiro,

c Especialização em Comunicação e Saúde pela Fundação Oswaldo Cruz.

\section{RESUMO}

Este trabalho tem como objetivo descrever, por meio de um relato de experiência, o processo de elaboração do Plano de Preservação Digital da VideoSaúde - Distribuidora (VSD), um serviço vinculado ao Instituto de Comunicação e Informação Científica e Tecnológica em Saúde (Icict), unidade técnico-científica da Fundação Oswaldo Cruz (Fiocruz). Resultado de um conjunto de ações de preservação da Fiocruz, o Plano de Preservação Digital visa contemplar os documentos audiovisuais digitais da VSD, traçando uma estratégia de gestão e preservação a ser executada em curto prazo. A estratégia escolhida procurou se pautar por diretrizes sólidas de preservação digital, em especial a norma OAIS, por meio da adoção do Archivematica, repositório digital de código aberto. A estrutura desenvolvida para o plano se baseou em modelos de referência e procurou dar conta das principais necessidades da VSD, a fim de que seu acervo audiovisual possa estar devidamente preservado e acessível para as futuras gerações.

Palavras-chave: Preservação digital; Plano de preservação digital; Documentos audiovisuais; Repositórios digitais; Modelo OAIS. 


\section{ABSTRACT}

This work aims to describe, through an experience report, the preparation process of the Digital Preservation Plan of VideoSaúde - Distribuidora (VSD), a service linked to the Institute of Scientific and Technological Communication and Information in Health (Icict), technical-scientific unit of the Oswaldo Cruz Foundation (Fiocruz). Result of a set of preservation actions developed by Fiocruz, the Digital Preservation Plan aims to contemplate VSD digital audiovisual assets, outlining a management and preservation strategy to be implemented in the short term. The chosen strategy sought to be guided by solid digital preservation guidelines, especially the OAIS standard, through the adoption of Archivematica, an open source digital repository. The structure developed for the plan was based on reference models and attempted to address the main needs of VSD, so that its audiovisual collection can be properly preserved and accessible for future generations.

Keywords: Digital preservation; Digital preservation plan; Audiovisual documents; Digital repositories; OAIS model.

\section{RESUMEN}

El objetivo de este trabajo es describir, a través de un informe de experiencia, el proceso de preparación del Plan de Preservación Digital de VideoSaúde - Distribuidora (VSD), un servicio vinculado al Instituto de Comunicación e Información Científica y Tecnológica en Salud (Icict), unidad técnico-científica de la Fundación Oswaldo Cruz (Fiocruz). Resultado de un conjunto de acciones de preservación de Fiocruz, el Plan de Preservación Digital tiene como objetivo contemplar documentos audiovisuales digitales VSD, esbozando una estrategia de gestión y preservación que se ejecutará en el corto plazo. La estrategia elegida buscaba guiarse por pautas sólidas de preservación digital, especialmente el estándar OAIS, a través de la adopción de Archivematica, un repositorio digital de código abierto. La estructura desarrollada para el plan se basó en modelos de referencia y buscó dar cuenta de las principales necesidades de VSD, de modo que su colección audiovisual se pueda preservar adecuadamente y sea accesible para las generaciones futuras.

Palabras clave: Preservación digital; Plan de preservación digital; Documentos audiovisuales; Repositorios digitales; Modelo OAIS.

Este artigo compõe o Dossiê Preservação Digital.

Contribuição dos autores:

Concepção e desenho do estudo: Marco Dreer Buarque, João Guilherme Nogueira Machado e Eliane Batista Pontes.

Aquisição, análise ou interpretação dos dados: Marco Dreer Buarque, João Guilherme Nogueira Machado e Eliane Batista Pontes. Redação do manuscrito: Marco Dreer Buarque, João Guilherme Nogueira Machado e Eliane Batista Pontes.

Revisão crítica do conteúdo intelectual: Marco Dreer Buarque, João Guilherme Nogueira Machado e Eliane Batista Pontes.

Declaração de conflito de interesses: não há.

Fontes de financiamento: Marco Dreer Buarque foi bolsista do PRESERVO - Complexo de Acervos da Fiocruz financiado com recursos via Banco Nacional de Desenvolvimento Econômico e Social (BNDES).

Considerações éticas: não há.

Agradecimentos/Contribuições adicionais: Cleomar Huche Lopes e Karina Veras Praxedes dos Santos.

Histórico do artigo: submetido: 06 maio 2020 | aceito: 22 jul. 2020 | publicado: 30 set. 2020.

Apresentação anterior: não houve.

Licença CC BY-NC atribuição não comercial. Com essa licença é permitido acessar, baixar (download), copiar, imprimir, compartilhar, reutilizar e distribuir os artigos, desde que para uso não comercial e com a citação da fonte, conferindo os devidos créditos de autoria e menção à Reciis. Nesses casos, nenhuma permissão é necessária por parte dos autores ou dos editores. 


\section{INTRODUÇÃO}

A preservação digital é um campo que se amplia no século XXI como resposta à presença pervasiva dos documentos digitais, sobretudo nas instituições responsáveis pela sua gestão e preservação com vistas ao acesso contínuo em longo prazo. Se, por um lado, os documentos analógicos têm sua expectativa de vida limitada por fatores como estado de conservação, condições de guarda e controle ambiental, os documentos digitais apresentam uma fragilidade ainda maior, por dependerem de um conjunto de componentes tecnológicos como hardware, software, sistema operacional, interface etc. Todavia tal fragilidade não reside apenas na obsolescência de cada um desses componentes, mas também na necessidade de administrar todo o ambiente digital. Faz-se necessário, portanto, um gerenciamento ativo do ambiente, de maneira ininterrupta, para que as informações digitais nele contidas possam sobreviver por um longo prazo.

Este é um estudo descritivo, do tipo relato de experiência, sobre o desenvolvimento do Plano de Preservação Digital da VideoSaúde - Distribuidora (VSD), um serviço vinculado ao Instituto de Comunicação e Informação Científica e Tecnológica em Saúde (Icict), unidade técnico-científica da Fundação Oswaldo Cruz (Fiocruz). A VSD é responsável por produzir, captar, gerenciar, preservar e veicular conteúdos audiovisuais relacionados ao campo da saúde pública, tendo como foco a produção de vídeos. Destaca-se também pela veiculação de conteúdo audiovisual no campo da saúde coletiva, em emissoras públicas, educativas e comunitárias. Conta com 21 colaboradores, entre servidores, estagiários e bolsistas, distribuídos em apoio às atividades de três grandes áreas: Acervo, Produção e Distribuição.

O Plano de Preservação Digital da VSD está inserido no contexto de conscientização e fortalecimento da cultura institucional da Fiocruz a respeito da relevância do desenvolvimento de estratégias sedimentadas de preservação digital. O plano está subordinado ao Programa de Preservação Digital de Acervos da Fiocruz, que, por sua vez, está condicionado à Política de Preservação dos Acervos Científicos e Culturais da Fiocruz, lançada em 2018 no escopo do projeto Preservo - Complexo de Acervos da Fiocruz, sobre o qual trataremos adiante.

A VSD foi uma das instâncias pioneiras da Fiocruz a desenvolver um plano de preservação digital, em consequência de decisão tomada pelo Comitê Gestor do Preservo. Tal decisão não teve caráter aleatório, mas acabou por refletir, em primeiro lugar, os avanços alcançados nos últimos anos pela VSD e sua equipe técnica no que tange aos estudos e às práticas de preservação digital, por meio da adoção paulatina de fluxos de trabalho que pudessem aprimorar a produção, a gestão e a preservação dos seus documentos digitais. Em segundo lugar, a VSD também esteve na vanguarda, dentro do contexto da Fiocruz, na realização de testes com o software Archivematica, sistema gratuito de preservação digital de código aberto, inaugurando estrategicamente uma tendência que deverá se ampliar para a instituição como um todo. Um terceiro aspecto foi justamente a natureza do acervo da VSD, em grande medida baseado em documentos audiovisuais, tendo como objeto principal o vídeo (tanto analógico quanto digital).

Comparados a outros gêneros documentais, o audiovisual apresenta maior complexidade, sobretudo o vídeo digital, cuja estrutura necessariamente deve possuir um contêiner, um ou mais codecs ${ }^{i}$, além de outros elementos acessórios. O plano da VSD pode, portanto, ser uma ação estratégica, pois abre o caminho para que, na sequência, unidades na Fiocruz detentoras de acervos com documentos de característica menos complexa possam vir a ser contempladas com mais agilidade.

O objetivo deste trabalho é descrever o processo de elaboração do Plano de Preservação Digital da VSD, elencar as principais referências utilizadas e as etapas que constituem o documento, bem como os desafios encontrados para a sua consecução. Uma vez que um plano de preservação é um documento eminentemente de caráter prático, este relato reflete tal inclinação, pois igualmente tem o objetivo de lançar luz sobre

i Codec: Acrônimo de codificador/decodificador, dispositivo de hardware ou software que codifica/decodifica sinais, responsável também pela compressão dos arquivos digitais de vídeo. 
os aspectos práticos envolvidos (incluindo, por exemplo, fluxos de trabalho, ferramentas, hardwares e softwares) nas estratégias voltadas para a preservação dos documentos digitais da VSD. É importante salientar que, em um primeiro momento, o foco das estratégias, procedimentos e ações contidos no plano está voltado para os documentos audiovisuais digitais de cunho arquivístico da VSD. Portanto, as coleções serão contempladas em um segundo momento de desenvolvimento e atualização do documento.

Entre os diferentes gêneros documentais que devem ser contemplados pela preservação digital encontra-se o audiovisual, que possui características e complexidade muito particulares. Em comparação aos documentos tradicionais em papel, os documentos audiovisuais são mais vulneráveis a danos causados por manuseio inadequado, equipamentos mal conservados e armazenamento precário. A International Association of Sound and Audiovisual Archives (IASA) destaca a fragilidade inerente aos documentos audiovisuais: "Textos impressos ou manuscritos, assim como documentos fixados em película, podem se manter inteiramente legíveis mesmo quando danificados; por outro lado, a natureza contínua e baseada na duração temporal dos documentos audiovisuais implica em que qualquer comprometimento na integridade do documento resulte na perda da informação"1.

Qualquer instituição que possua em seu acervo documentos audiovisuais e que esteja elaborando estratégias de preservação digital deve necessariamente atentar para as particularidades desse gênero em específico, sob pena de comprometer ou colocar em risco o seu patrimônio audiovisual. Ray Edmondson oferece a seguinte definição de documentos audiovisuais: "Gravações visuais (com ou sem banda de som [soundtrack]) independente [da sua base física] do seu suporte e processo de gravação usado, como filmes, [filmstrips] diafilme, microfilmes, diapositivos, fitas magnéticas, cinescópios [kinescopes], videogramas [videograms], videotapes - fitas de vídeo (videotape, videodiscos), discos ópticos legíveis por laser (a) planeados para recepção pública quer através de televisão ou por meio de projeção em écrans ou por quaisquer outros meios (b) destinados a ser postos à disposição do público"2.

No que se refere à preservação digital, a referência mais sólida é o Open Archival Information System (OAIS), desenvolvido pelo Consultative Comitee for Space Data Systems (CCSDS) e aprovado como padrão ISO 14721:2003 - posteriormente revisado em 2012 ${ }^{3}$. Trata-se de um modelo conceitual, que reúne noções e processos relacionados à preservação da informação digital, estabelecendo um consenso sobre um conjunto de práticas. Por ser um modelo conceitual, o OAIS não trata de ferramentas ou soluções tecnológicas, sendo um documento dedicado a apontar para os processos e atividades que perpassam a preservação das informações digitais. "Este modelo é um esquema conceitual que disciplina e orienta um sistema para a preservação e manutenção do acesso à informação digital por longo prazo. O objetivo do modelo é ampliar a consciência e a compreensão dos conceitos relevantes para a preservação de objetos digitais, especialmente entre instituições não arquivísticas; definir terminologias e conceitos para descrever e comparar modelos de dados e arquiteturas de arquivos; ampliar o consenso sobre os elementos e os processos relacionados à preservação e acesso à informação digital; e criar um esquema para orientar a identificação e o desenvolvimento de padrões"4.

Outra referência importante para a preservação digital é a noção de Repositório Arquivístico Digital Confiável (RDC-Arq), modelo proposto pelo Research Libraries Group (RLG) e pelo Online Computer Library Center (OCLC), que constitui "um complexo que apoia o gerenciamento dos materiais digitais, pelo tempo que for necessário, e é formado por elementos de hardware, software e metadados, bem como por uma infraestrutura organizacional e procedimentos normativos e técnicos"s.

Os repositórios digitais arquivísticos devem preferencialmente estar em conformidade com um modelo de referência, tal como o padrão OAIS, por ser uma solução voltada para a presunção da autenticidade, a preservação e o acesso de longo prazo aos documentos. Critérios de auditoria e certificação de repositório também devem ser considerados, sobretudo o Audit and Certification of Trustworthy Digital Repositories ${ }^{6}$ (norma ISO 16363, também conhecida como TDR), que fornece diretrizes para medir a confiabilidade de um repositório digital. Embora não seja uma norma, outra referência importante para o campo da 
preservação digital são os Níveis de Preservação Digital7, desenvolvidos pela National Digital Stewardship Alliance (NDSA), que estabelecem um conjunto de recomendações e práticas que auxiliam as instituições na avaliação da preservação digital dos seus acervos, a partir de quatro níveis progressivos.

Além de bases conceituais bem sedimentadas, tais como o OAIS e o RDC-Arq, a preservação digital deve necessariamente envolver também o uso de um conjunto de estratégias, que inclui ações como migração, emulação, resfrescamento, conservação de hardware e software, reprografia, normalização, entre outras ${ }^{8}$. Todas essas estratégias visam, de diferentes maneiras, atenuar os processos de obsolescência que impactam as informações digitais, de modo que ao menos algumas delas devem ser incluídas em um plano de preservação digital.

Para que estratégias de preservação digital possam alcançar resultados mais substanciais, são recomendáveis instrumentos que possibilitem melhor identificar as ações e as etapas necessárias, principalmente no contexto das instituições de guarda. Nesse sentido, é possível observar, sobretudo nas últimas duas décadas, a produção cada vez mais frequente de planos de preservação digital, por meio dos quais as instituições procuram, de maneira mais formalizada e estruturada, elencar os passos necessários para preservar os seus conteúdos digitais.

Este trabalho também tem o intuito de auxiliar os profissionais que pretendam elaborar um plano de preservação para suas instituições, podendo servir de insumo ao menos para a estruturação do documento. No contexto brasileiro ainda há poucas iniciativas, por parte das instituições, voltadas para a elaboração de políticas, programas e planos de preservação digital ${ }^{9}$. Ainda que seja possível observar um aprofundamento no debate sobre a preservação digital no país, tal tendência ainda não resultou em documentos consistentes que explicitem, de maneira formalizada, as estratégias adotadas pelas instituições brasileiras nesse campo ${ }^{\text {ii. }}$.

Portanto, a iniciativa da elaboração de um plano de preservação digital por parte da Fiocruz é singular no contexto brasileiro, podendo ser uma importante contribuição para instituições nacionais que ensejem produzir documentos dessa natureza, a fim de melhor embasar as suas estratégias de gestão e preservação digital.

\section{METODOLOGIA APLICADA A UM RELATO DE EXPERIÊNCIA: A PRESERVAÇÃO DE OBJETOS DIGITAIS}

A metodologia utilizada neste trabalho consiste em um estudo descritivo, do tipo relato de experiência, elaborado no contexto das ações de preservação digital da Fiocruz, mais especificamente aquelas realizadas junto ao acervo audiovisual da VSD. Partindo de levantamento bibliográfico constituído de normas, artigos científicos e páginas web, o estudo tem o intuito de descrever uma experiência localizada (a elaboração do Plano de Preservação Digital da VSD) e apontar para a importância da adoção de planos de preservação digital por parte dos acervos audiovisuais. Para tanto, são levantados modelos de planos de preservação digital disponíveis em fontes estrangeiras, incluindo a análise de suas estruturas. O relato de experiência em questão é a descrição de uma vivência profissional, visando contribuir para a reflexão e o debate sobre a preservação digital aplicada aos acervos audiovisuais.

A fim de que possamos abordar o Plano de Preservação Digital da VSD em suas especificidades, fazse necessário estabelecermos previamente as devidas distinções entre as noções de política e plano de preservação digital, de modo a evitar eventuais imprecisões conceituais. Em suas Recomendações para

\footnotetext{
ii De acordo com pesquisa elaborada por Silva Júnior e Mota9, no Brasil apenas a Câmara dos Deputados e a Universidade Estadual de Campinas desenvolveram uma política de preservação digital e a disponibilizaram nos seus websites, e mesmo instituições e empresas que desenvolveram projetos de digitalização dos seus acervos não instituíram políticas de preservação digital. Mais recentemente, outras instituições que elaboraram as suas políticas de preservação digital foram a Pinacoteca de São Paulo e a Unesp, ambas editadas em 2017.
} 
elaboração de política de preservação digital, o Arquivo Nacional define uma política de preservação digital como sendo “(...)um instrumento institucional por meio do qual os órgãos e entidades definem sua visão sobre a preservação desses documentos, abrangendo princípios gerais, diretrizes e responsabilidades, que orientem a elaboração de programas, projetos, planos e procedimentos, com vistas à preservação e acesso a documentos arquivísticos digitais autênticos"10.

A Canadian Heritage Information Network (CHIN) aponta que uma política de preservação digital deve responder a questões como: 'O que deve ser preservado?'; 'Por quanto tempo?'; 'Quem terá acesso aos ativos digitais?' e 'De que maneira os ativos digitais podem ser utilizados?'. De acordo com o modelo estruturado pela CHIN, uma política deve apresentar a perspectiva mais elevada do programa de preservação digital de uma instituição, refletindo os recursos atuais do seu programa, e não as suas capacidades futuras. A política também deve apontar para o plano de preservação digital no que diz respeito a prioridades e metas de curto prazo. Por fim, uma política deve documentar o processo de aprovação e manutenção da própria política, além de indicar os eventos que possam desencadear a sua atualização ${ }^{11}$.

A adoção de uma política de preservação digital é a maneira mais eficaz de assegurar o armazenamento e o uso de informações em um longo prazo, de modo que a ausência de políticas por parte das instituições pode indicar uma falta de embasamento técnico sobre as estratégias de preservação digital ${ }^{12}$. O projeto SCAPE aponta que as políticas são instrumentos essenciais, pois contribuem para conscientizar e orientar os setores de uma instituição a respeito de suas atividades relacionadas à preservação digital ${ }^{13}$. São instrumentos úteis, portanto, no trabalho diário dos profissionais responsáveis por acervos documentais, que poderão tomar decisões mais bem fundamentadas sobre as ações necessárias de preservação. Além disso, produtores e usuários dos acervos também poderão ser beneficiados pelas políticas de preservação, uma vez que estas lhes darão uma noção mais precisa sobre as principais decisões tomadas pela instituição em relação à manutenção do seu acervo - incluindo o que será preservado, por quanto tempo, de que maneira estará acessível etc.

Já um plano de preservação é um documento que envolve níveis mais específicos e concretos, uma vez que propõe um plano de ação voltado à preservação de um conjunto de objetos, visando a um determinado objetivo. Aspectos envolvendo planejamento de preservação são abordados no projeto PLANETS, que oferece a seguinte definição de plano de preservação: "Um plano de preservação define uma série de ações de preservação a serem executadas por uma instituição responsável em função de um risco identificado para um determinado conjunto de objetos ou documentos digitais (denominado coleção). O Plano de Preservação leva em consideração as políticas de preservação, obrigações legais, limitações organizacionais e tecnológicas, necessidades do usuário, objetivos de preservação e descreve o contexto de preservação, as estratégias de preservação avaliadas e a escolha resultante para uma estratégia, incluindo a fundamentação para esta escolha. Também especifica uma série de etapas ou ações (denominadas 'plano de ação para preservação'), juntamente com responsabilidades, regras e condições para execução junto à coleção. Desde que as ações, sua implantação e o ambiente tecnológico permitam, este plano de ação é uma definição de um fluxo de trabalho factível" (tradução nossa) ${ }^{14}$.

De acordo com a CHIN, um plano de preservação digital é um documento que deverá idealmente absorver elementos oriundos tanto de um inventário quanto de uma política, geralmente produzidos anteriormente, e responder à seguinte pergunta: "Como a política de preservação digital pode ser implementada da melhor forma possível?”" . O plano seria, portanto, um documento diretamente relacionado à política e ao programa de preservação digital, devendo estar sempre subordinado a ambos. O plano deverá exigir informações da instituição como orçamento, recursos humanos que poderão ser dedicados ao trabalho de preservação, conhecimento sobre as tecnologias e habilidades tecnológicas atuais, entre outros itens. A estrutura do plano também deve fazer referência às práticas e padrões já existentes, às quais a instituição pode recorrer de acordo com suas necessidades e habilidades. Em suma, um plano reuniria, em um mesmo documento, um estudo de caso das necessidades de preservação digital da instituição, a estratégia e a solução tecnológica 
escolhidas como resultado do estudo de caso, além dos procedimentos detalhando o modo pelo qual o plano deverá ser executado diariamente.

A elaboração do Plano de Preservação Digital da VSD teve início no segundo semestre de 2019 e foi concluída em abril de 2020, contando com a participação de profissionais da própria VSD, especificamente os diretamente envolvidos nas etapas de produção e preservação, além da contribuição de membros do Comitê Gestor do Preservo. Conforme apontamos acima, a escolha da VSD como uma das primeiras instâncias da Fiocruz a ter um plano de preservação digital contemplado pelas ações do Preservo se deveu sobretudo pelas suas ações relacionadas à preservação digital nos anos mais recentes, tanto por meio da estruturação de fluxos de trabalhos voltados para a gestão do seu acervo digital como um todo, quanto pela iniciativa de inaugurar testes no software Archivematica - ferramenta aberta que implementa, de maneira mais ou menos automatizada, requisitos sólidos de preservação digital em consonância com o modelo OAIS (Open Archival Information System).

Os planos de preservação digital que virão a ser elaborados, destinados a diferentes unidades da Fiocruz, foram definidos como sendo instrumentos diretamente submetidos ao Programa de Preservação Digital. A execução dos planos teve como motivação colocar imediatamente em prática ações de preservação específicas para cada uma das unidades, uma vez tendo o programa um caráter mais conceitual, de abordagem mais genérica e ampla. Os planos, ao contrário, além de apontarem para ações a serem adotadas em curto prazo, pretendem ser documentos que traduzem as unidades em suas especificidades e demandas particulares, elencando práticas e ferramentas necessárias para a preservação de determinados conjuntos documentais digitais.

Para a elaboração de um plano de preservação digital, foi necessário o levantamento prévio de modelos que pudessem auxiliar na composição do documento. A busca por um modelo também se justificou pela necessidade de se tentar seguir uma estrutura formal, já testada e utilizada por instituições de referência no campo da preservação digital - e da curadoria digital de maneira mais ampla. Não foi possível identificar no Brasil planos de preservação digital que ao menos pudessem estar disponíveis publicamente, ainda que haja políticas voltadas para o campo ${ }^{9}$. Portanto, a solução natural foi buscar modelos e referências desenvolvidos internacionalmente, tanto aqueles relatados em trabalhos acadêmicos quanto os disponíveis nos próprios websites das instituições ${ }^{15-19}$.

Entre os modelos avaliados, aquele que apresentou ser o mais bem descrito em suas diversas seções foi o desenvolvido pela Canadian Heritage Information Network (CHIN), organização governamental canadense que oferece apoio às instituições ligadas ao patrimônio do país. Em 2011, a CHIN realizou uma ampla pesquisa nacional sobre a situação da preservação digital nos museus canadenses, a qual apontou que, embora a grande maioria dos museus abrigasse documentos digitais em seus acervos, quase a totalidade deles não possuía uma política ou plano formal para a preservação de longo prazo desses documentos. Em resposta a essa lacuna, a CHIN desenvolveu um 'kit de ferramentas', disponível on-line, denominado "Digital Preservation Toolkit"11, composto por recursos produzidos pelo CHIN e seus parceiros, objetivando auxiliar museus a desenvolver políticas, planos e outros procedimentos.

O 'kit de ferramentas' elaborado pela CHIN envolve o uso de fontes de referência, que apoiam ações de preservação, e estas, por sua vez, devem resultar em dois documentos: uma política e um plano de preservação digital, nesta ordem. Estes documentos devem ser precedidos por um inventário do acervo digital, instrumento que procura jogar luz sobre o cenário atual de uma instituição, sendo um levantamento inicial que possa indicar ao menos a quantidade de objetos digitais armazenados e os gêneros documentais que compõem o acervo. Essas informações disponíveis em um inventário podem, ao fim e ao cabo, auxiliar na tomada de decisões relativas à preservação digital. Inventários podem variar substancialmente em complexidade e amplitude, mas, mesmo quando sumários, podem ser extremamente úteis enquanto visão geral de um acervo digital. A VSD já havia elaborado um inventário parcial dos documentos audiovisuais 
digitais sob sua guarda, incluindo a sua localização, de modo que esse levantamento foi importante como referência inicial para o plano de preservação digital, sendo incorporado ao mesmo.

Como já mencionado acima, o plano é uma espécie de estudo de caso que, em um primeiro momento, aponta para a situação atual da instituição, incorporando algumas informações essenciais (como, por exemplo, as necessidades de preservação digital, referências à política e ao inventário de objetos digitais, recursos financeiros, padrões e ferramentas utilizados etc.). Em seguida, é possível considerar várias possibilidades de estratégias de preservação digital a serem adotadas pela instituição e avaliar as vantagens e desvantagens de cada uma delas. Seleciona-se, por fim, uma estratégia em específico, justificando as razões da escolha.

O artigo de Becker, Kulovitz, Guttenbrunner, Strodl, Rauber e Hofman ${ }^{15}$ sugere qual deveria ser a estrutura de um plano de preservação, com a descrição de cada elemento, a saber: Identificação; Situação e gatilhos; Descrição do cenário institucional; Descrição da coleção; Requisitos para preservação; Elementos para seleção de uma estratégia de preservação; Custos; Funções e responsabilidades; e Plano de ação para preservação.

Inspirado no supracitado artigo e no modelo desenvolvido pela CHIN, estruturamos o plano de preservação digital da VSD, considerando também as especificidades e o contexto da VSD. Segue abaixo a estrutura do plano, dividido em seções e subseções:

- Cenário institucional

- Estrutura organizacional

- Políticas de preservação relacionadas

- Descrição do acervo

- Identificação e escopo

- Aspectos organizacionais

- Aspectos técnicos

- Requisitos do usuário

- Práticas correntes de preservação

- Avaliação de riscos

- Possíveis ameaças

- Mitigação de riscos

- Planos de Preservação

- Estratégias de preservação avaliadas

- Identificação e justificativa do Plano de Preservação selecionado

- Funções e responsabilidades

- Custos e fontes de financiamento

- Revisão do Plano de Preservação

- Detalhamento do Plano de Preservação selecionado

Alguns elementos desta estrutura merecem ser destacados, sobretudo para o caso específico aqui analisado. Como o acervo da VSD é constituído majoritariamente de vídeos (arquivos nato digitais e digitalizados), na seção 'Descrição do acervo' foi preciso considerar a particularidade desse tipo documental, sobretudo no que se refere ao grande volume de armazenamento necessário à sua guarda em comparação 
a documentos em papel ou até mesmo fotografias. Nesse sentido, foi fundamental o levantamento de um inventário do acervo audiovisual (quadro 1), ainda que parcial, para que, mais à frente, fosse possível avaliar os impactos relativos tanto aos custos quanto aos investimentos tecnológicos.

\section{Quadro 1 - Inventário parcial do acervo audiovisual digital da VSD}

\begin{tabular}{|l|l|l|}
\hline \multicolumn{2}{|l|}{ Principais formatos analógicos } & Estrutura arquivística digital \\
\hline Formato & Quantitativo & Volume estimado total nato digital: 80TB \\
\hline VHS & 2.185 & Volume tratado*: 2.32 TB: \\
SVHS & 168 & 23 dossiês - série 'Eventos' (não editado); \\
BETACAM & 1.109 & 30 dossiês - série 'Eventos' (editado) \\
DVCAM & 1.461 & 08 dossiês - série 'Programas' VideoSaúde \\
DVD & 2.351 & Cópias de segurança (Backup) --LTO 6 \\
MINIDV & 1.501 & *Considera-se volume tratado o material que já \\
& & está sendo identificado e submetido aos novos \\
& & fluxos de procedimento técnico. \\
& & \\
\hline
\end{tabular}

Fonte: João Guilherme Nogueira Machado, Eliane Batista Pontes (2019).

Nesta seção também são mencionados os principais formatos de vídeo digital que constituem o acervo, bem como as tecnologias utilizadas para o seu armazenamento. São listadas aqui as principais necessidades observadas referentes à preservação digital - como, por exemplo, investimentos em infraestrutura tecnológica - assim como os diferentes padrões de metadados necessários para descrever os objetos audiovisuais digitais. São relacionados também os principais requisitos dos usuários do acervo digital da VSD, sobretudo dos próprios profissionais da unidade, como uma forma de apontar para os aspectos que deverão ser contemplados pelas ações do plano de preservação propriamente dito. Esta seção é, portanto, de maneira geral, um amplo painel do cenário corrente da VSD, uma espécie de diagnóstico das suas atuais condições e dos investimentos dedicados à preservação digital.

A seção seguinte envolve uma breve avaliação de riscos, tema bastante caro à preservação digital. Devem ser relacionados aqui os principais riscos relacionados à gestão e preservação do acervo digital e os possíveis meios de mitigá-los. O exercício de tentar identificar os riscos também será de grande importância para a elaboração das estratégias de preservação digital adiante.

As duas últimas seções envolvem a descrição detalhada dos planos de preservação digital. Ao contrário das seções anteriores, que davam conta de avaliar a situação corrente, aqui pretende-se projetar cenários futuros, os quais possam conter soluções viáveis para aprimorar as condições de preservação digital do acervo analisado. É possível e recomendável projetar mais de um cenário ou estratégia que contenham diferentes abordagens e que façam uso de soluções tecnológicas diversas. Pode-se, por exemplo, avaliar uma estratégia que inclua uma abordagem de solução simples, envolvendo apenas a dispersão geográfica dos meios de armazenamento digital e ao mesmo tempo. descrever uma segunda estratégia, mais complexa, que inclua maiores investimentos tecnológicos e em conhecimento - como, por exemplo, a adoção de um repositório digital confiável.

Caso se opte pela avaliação de diferentes estratégias, o documento deve relacionar as vantagens e desvantagens da adoção de cada uma delas, as funções e responsabilidades envolvidas, bem como os principais custos e fontes de financiamento necessários para a sua manutenção. No caso específico do plano da VSD, optamos por avaliar uma única estratégia, que será apresentada na seção 4. 
Reciis - Rev Eletron Comun Inf Inov Saúde. 2020 jul.-set.;14(3):734-50 | [www.reciis.icict.fiocruz.br] e-ISSN 1981-6278

\section{CONTEXTO, CENÁRIO E AÇÕES DE PRESERVAÇÃO NO ÂMBITO INSTITUCIONAL DA VIDEOSAÚDE}

A Fiocruz possui uma grande variedade de acervos, incluindo edificações, arquivos históricos e bibliográficos, coleções biológicas, iconográficos e audiovisuais, entre outros, que estão associados ao desenvolvimento da ciência e tecnologia em benefício da saúde pública brasileira. O comprometimento com a manutenção desses bens científicos e culturais levou a Fiocruz a elaborar políticas específicas e um projeto voltado para a preservação de seus acervos.

Em 2010, a Casa de Oswaldo Cruz (COC), unidade orientada para a gestão e preservação cultural da Fiocruz, teve a iniciativa de elaborar o projeto Preservo - Complexo de Acervos da Fiocruz, visando à preservação dos seguintes acervos da instituição: Arquivístico, que inclui os documentos textuais, iconográficos, sonoros, filmográficos etc.; Arquitetônico (Núcleo Histórico de Manguinhos); Museológico; Bibliográfico; além das Coleções Biológicas.

O Preservo veio estabelecer uma nova ordem na gestão dos acervos, visando integrá-los por meio de uma rede formada entre os setores que custodiam os acervos na Fiocruz. Conjugado às ações de preservação, o projeto se propôs também a modernizar a infraestrutura tecnológica e expandir o acesso da população em geral ao patrimônio científico e cultural da instituição.

As ações de preservação passam pela elaboração de políticas que estabeleçam princípios e diretrizes que visam agregar o conjunto dos acervos da instituição. Com esta compreensão foi então elaborada a Política de Preservação dos Acervos Científicos e Culturais da Fiocruz ${ }^{20}$, em 2018, desenvolvida pelo Comitê Gestor do Preservo, uma instância colegiada de caráter permanente com a função de formular, orientar e articular as ações referentes aos objetivos institucionais.

Diretamente submetido à Política, foi desenvolvido em 2020 o Programa de Preservação Digital dos Acervos Científicos e Culturais da Fiocruz (PPD), que estabelece as diretrizes para a constituição da infraestrutura física e lógica para o armazenamento de documentos digitais. Por desempenhar importante papel frente às discussões relativas aos documentos audiovisuais, as práticas da VSD vêm servindo de referência no que se refere ao tratamento desse gênero documental na Fiocruz, incluindo algumas diretrizes presentes no PPD.

Cabe destacar também a elaboração da Política de Acesso Aberto ao Conhecimento da Fiocruz ${ }^{21}$, instituída em 2014, que define o acesso que a população deve ter à produção científica da instituição, estando diretamente relacionado às demandas por comunicação e divulgação dos acervos estabelecidos na Lei de Acesso à Informação (LAI). Outra iniciativa foi a Política de Comunicação da Fiocruz ${ }^{22}$, de 2016, com a finalidade de orientar e normatizar o campo da comunicação na instituição.

Serviço vinculado ao Icict, a VideoSaúde Distribuidora (VSD) iniciou suas atividades em 1988, constituída para ser uma proposta de trabalho voltada para a comunicação pública e tendo como objeto os documentos audiovisuais. Além de contribuir para o legado da comunicação e da saúde na instituição, tornou-se um espaço de guarda e preservação da memória da saúde pública brasileira nesse gênero documental.

A VSD possui características singulares, atuando como um Centro de Documentação Audiovisual sobre saúde pública e custodiando um significativo acervo arquivístico de vídeos de caráter permanente - segundo o Código de Classificação $0^{\text {iii }}$ e a Tabela de Temporalidade e Destinação $0^{\text {iv }}$ de documentos para atividades finalísticas da Fiocruz. O acervo se constituiu a partir da reunião das produções em vídeo realizadas na Fiocruz, seguida da catalogação, geração de cópias e divulgação desses documentos, estabelecendose, assim, a base de atuação da VSD. O acervo foi se ampliando ao longo dos anos, tanto pela inclusão

iii http://www.sigda.fiocruz.br/images/pdf/Codigo_de_classificacao de documentos_de_arquivo_da_Fiocruz_MEIO FIM dez2018.pdf.

iv http://www.sigda.fiocruz.br/images/pdf/TTD_PARA_ATIVIDADES_FIM_DA_FUNDACAO_OSWALDO_CRUZ.pdf. 
de gravações de atividades e eventos técnicos e científicos da Fiocruz, quanto pela produção de vídeos documentários sobre temas da saúde.

O acervo da VSD vem sendo formado por documentos arquivísticos, mas também por uma coleção, resultado de sua atividade de trabalho. A vasta coleção de títulos especializados em saúde retrata a construção da história da saúde pública brasileira das últimas três décadas. O acervo é constituído majoritariamente de material em meio analógico (fitas de vídeo de diversos formatos), mas vem expandindo cada vez mais a produção em meio digital, demandando crescente espaço de armazenamento. Trata-se de um acervo de características híbridas, tanto no que se refere à natureza dos materiais que custodia (arquivo e coleções temáticas) quanto aos suportes e meios (fitas magnéticas, discos ópticos, meios analógico e digital) que registram os seus conteúdos.

Com vistas à ampliação do acervo, a VSD passou também a organizar mostras de vídeo, com o objetivo de fazer circular o conhecimento sobre a saúde para a população brasileira, além de se estabelecer como referência em vídeos com a temática da saúde. A disseminação se deu a partir da implantação de videotecas, onde estão disponíveis os documentos audiovisuais para consulta ou empréstimo, passando, em seguida, a exibir os vídeos do acervo em canais de TVs públicas e em mostras itinerantes.

O acervo de vídeo da VSD é constituído predominantemente de documentários, além de outras linguagens audiovisuais como a ficção e a animação, que abordam o tema da saúde em seus mais variados aspectos. Como vimos acima, é um acervo de natureza híbrida, composto de documentos arquivísticos e de uma coleção, registrados e catalogados no Banco de Recursos Audiovisuais em Saúde (BRAVS).

Os títulos pertencentes à coleção têm procedência diversa, oriundos desde entidades públicas e privadas relacionadas ao setor da saúde até organizações não governamentais e produtores independentes. Já os documentos arquivísticos correspondem às séries relativas à produção institucional, que incluem programas de TV, produções do Selo Fiocruz Vídeo, projetos de documentários e registros de eventos técnicos e/ou científicos da instituição.

O acervo é composto de aproximadamente 9.200 itens, o que corresponde a algo em torno de dez mil horas de conteúdo audiovisual sobre saúde, entre documentos analógicos e digitais. Os principais formatos analógicos de vídeo presentes no acervo são VHS, U-Matic, S-VHS, Betacam, DVCAM, MiniDV e DVD. Já entre os formatos de arquivo de vídeo digital encontram-se .mov, .m2t, .m2ts, .mp4, .avi e .avchd A estrutura arquivística digital, que se encontra em desenvolvimento, é composta por um volume estimado de dados de 80 Terabytes (TB), dos quais 2,32 TB estão tratados.

Em virtude da magnitude e alcance de suas atividades em pesquisa na área da saúde, a Fiocruz possui grande variedade de acervos científicos e culturais, sendo instituição estratégica para o Estado brasileiro e de excelência na área de pesquisa, atuando como agente fundamental na criação, execução e inovação de políticas públicas em saúde.

Ao compreender a comunicação e a informação científica como um direito humano fundamental, a Fiocruz vem desenvolvendo políticas e estratégias de preservação capazes de garantir e promover a manutenção de acesso aos conteúdos informacionais e ao conhecimento gerados pela instituição. Nesse âmbito, o Icict, unidade à qual a VSD se vincula, credita ao audiovisual um papel central na disseminação da informação e na preservação da memória da saúde pública brasileira.

Como vimos acima, o projeto Preservo, por meio do estabelecimento de políticas, programas e ações de preservação dos acervos científicos e culturais da Fiocruz, vem intensificando os debates acerca das estratégias de preservação do patrimônio audiovisual da instituição. As ações desenvolvidas pela VSD no âmbito desses debates, sobretudo no que tange à preservação digital, apontam para novas práticas de trabalho, incluindo a adoção de ferramentas de preservação voltadas para documentos arquivísticos audiovisuais. 
Os usos e demandas dos recursos audiovisuais na Fiocruz podem ser percebidos e refletidos nos diversos canais de comunicação e acesso à informação que utilizam vídeos, tanto para divulgar o conhecimento produzido pela instituição, quanto para registrar a sua memória. É, portanto, inegável o poder informativo, histórico e cultural dos registros audiovisuais. "Os documentos audiovisuais são tão importantes - em alguns casos mesmo mais importantes - quanto outros tipos de documentos e artefatos. A relativa novidade de sua invenção, seu caráter frequentemente popular e sua vulnerabilidade às rápidas mudanças tecnológicas não diminuem sua importância. Sua conservação e o acesso a eles devem ser garantidos, assim como os recursos necessários para isso”².

Nesse contexto, ficou evidenciada a necessidade de realizar estudos mais profundos e detalhados sobre estratégias de preservação digital do patrimônio científico e cultural da instituição. Seguindo orientações e recomendações estabelecidas pelo Conselho Nacional de Arquivos (CONARQ), o Grupo de Trabalho (GT) de Gestão e Preservação de Documentos Arquivísticos Digitais da Fiocruz foi então instituído em 2019, no qual a VSD representa o audiovisual enquanto gênero documental arquivístico constituinte do patrimônio da instituição.

\section{PLANO DE PRESERVAÇÃO DIGITAL DA VIDEOSAÚDE: O DIAGRAMA DOS FLUXOS DOS OBJETOS AUDIOVISUAIS}

Uma vez que a VSD já vinha realizando testes com o software Archivematica desde 2018, como resultado, a estratégia para o plano de preservação digital passou a incluir, enquanto etapa final, a plena adoção da ferramenta. Contando com significativa utilização por parte de diversas instituições de guarda, o Archivematica se fundamenta por sólidos requisitos de preservação digital, tendo como base o modelo conceitual OAIS ${ }^{23}$. Desenvolvido pela empresa canadense Artefactual, trata-se de um software livre e de código fonte aberto dedicado ao desenvolvimento de repositórios digitais.

Os testes com o Archivematica se inserem no contexto de remodelamento dos fluxos e ações de produção, processamento técnico, armazenamento e acesso ao acervo audiovisual da VSD, tendo como objetivo se aproximar dos requisitos mais atuais de preservação digital. Os fluxos de trabalho da VSD têm como base a criação de pacotes de informação de submissão (SIPs) ${ }^{\text {vi }}$ para admissão futura no Archivematica. Esta abordagem que faz uso de pacotes de informação é, portanto, o cerne da estratégia que compõe o Plano de Preservação Digital da VSD. "O pacote de informação visa reunir o objeto de dados e a informação de representação necessária para descrever corretamente o objeto de informação, e paralelamente, fornecer subsídios para sua preservação. A arquitetura lógica do pacote de informação consiste em manter o documento arquivístico digital junto à respectiva informação de representação, necessária para garantir autenticidade, correta interpretação e preservação em longo prazo. Desse modo, auxilia a comunidade designada no processo de busca e recuperação da informação de conteúdo contida nos documentos digitais”24.

Dessa forma, utilizar a abordagem dos pacotes de informação já é, em ampla medida, contemplar importantes requisitos da preservação digital. A estratégia adotada pela VSD envolve, portanto, a criação dos pacotes SIPs, os quais se tornarão pacotes AIPs somente quando forem admitidos no Archivematica. O documento relaciona também uma série de ferramentas de preservação digital, destinadas a objetivos específicos (quadro 2).

\footnotetext{
v Portaria da Presidência da Fiocruz 6069-2019-PR.

vi O modelo conceitual OAIS incorpora três tipos diferentes de pacote de informação: o Pacote de Informação para Submissão (Submission Information Package - SIP), o Pacote de Informação para Arquivamento (Archival Information Package - AIP) e o Pacote de Informação para Difusão (Dissemination Information Package - DIP).
} 


\section{Quadro 2 - Ferramentas de preservação digital utilizadas no plano}

\begin{tabular}{|c|c|c|}
\hline Ferramenta & Ação de utilização & Informações sobre \\
\hline MediaInfo & Extração de metadados técnicos embutidos. & $\underline{\text { https://mediaarea.net/pt/MediaInfo }}$ \\
\hline Robocopy & $\begin{array}{l}\text { Verificação de integridade e manutenção de } \\
\text { metadados técnicos. }\end{array}$ & $\begin{array}{l}\text { https://docs.microsoft.com/pt-br/ } \\
\text { windows-server/administration/windows- } \\
\text { commands/robocopy }\end{array}$ \\
\hline Md5Checker & $\begin{array}{l}\text { Verificação de integridade e fixidez dos } \\
\text { objetos digitais, por meio da geração de } \\
\text { valor de checksum (do tipo MD5). }\end{array}$ & http://getmd5checker.com/ \\
\hline DROID & $\begin{array}{l}\text { Descrição pormenorizada dos formatos } \\
\text { de arquivo digitais, a fim de auxiliar no } \\
\text { inventário. }\end{array}$ & $\begin{array}{l}\text { https://www.nationalarchives.gov.uk/ } \\
\text { information-management/manage- } \\
\text { information/preserving-digital-records/ } \\
\text { droid/ }\end{array}$ \\
\hline LibreOffice CALC & $\begin{array}{l}\text { Construção das planilhas de metadados } \\
\text { descritivos, em formato .csv. }\end{array}$ & $\begin{array}{l}\text { https://pt-br.libreoffice.org/descubra/ } \\
\text { calc/ }\end{array}$ \\
\hline
\end{tabular}

Fonte: Elaborado pelos autores (2020).

Ao fazer uso dos pacotes de informação, em particular, e do Archivematica, de maneira mais ampla, o fluxo de trabalho da VSD passa a se aproximar dos requisitos da norma OAIS, uma vez que as ações e procedimentos incluídos no plano também têm como objetivo oferecer algum nível de presunção de autenticidade dos documentos tratados. O software permite também oferecer maior automação dos seus processos, reunidos em uma única ferramenta, reduzindo assim o tempo dispensado nas ações de preservação digital. Por outro lado, é preciso destacar a complexidade do Archivematica, que exige mais tempo e conhecimentos envolvidos nos processos de instalação, configuração e customização, frequentemente exigindo treinamento intensivo por parte de seus usuários.

A seção referente ao detalhamento do plano de preservação é apoiada por um diagrama, que ilustra toda a estratégia adotada (figura 1). 
Autores: João Guilherme Nogueira Machado, Eliane Batista Pontes, Cleomar Huche Lopes

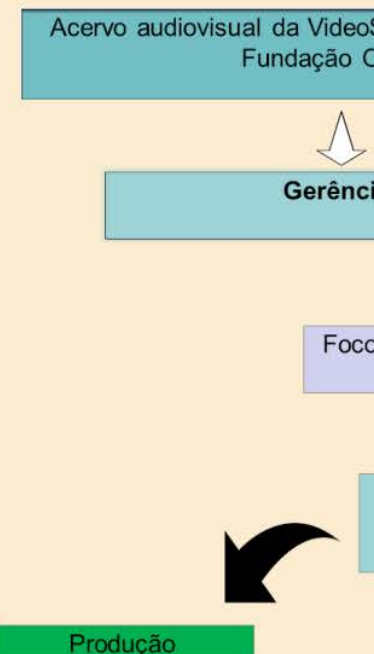

da VideoSaúde - Distribuidora/ Icict da

waldo Cruz

erência de Projeto Arquivistico

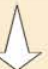

oco nos documentos arquivisticos audiovisuais digitais

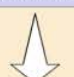

Estratégias de gestão e preservação de documentos arquivisticos audiovisuais digitais baseadas em recomendações do modelo OAIS e apoiadas por políticas, programas e planos de preservação institucionais.

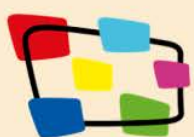

videosaúde

DISTRIBUIDORA DAFIOCRUZ

\section{L \\ Identificação e cadastro de material}

$$
\Rightarrow \text { inforn }
$$
produtor

$\rightarrow$ Informações descritivas

Mídias físicas com conteúdo intelectual em meio

digital para ingestão em storage

$\rightarrow$ Documentos permanentes conforme o Código de Classificação de Documentos da Fiocruz

Análise de conformidades com direitos autorais em consonância com a Política de Acesso aberto da Fiocruz

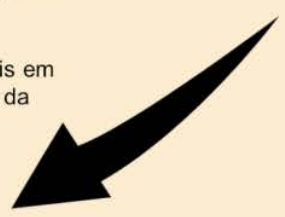

\section{Curadoria \\ $\rightarrow$ Avaliação de prioridades:}

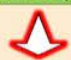

Admissão no software de preservação (Archivematica)/ Datacenter Fiocruz;

- Conteúdo em formato analógico com prioridade para digitalização;

> Manutenção de conteúdo em storage local.

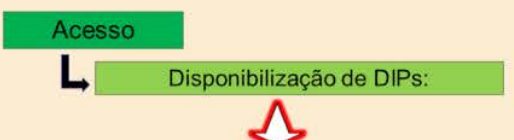

Repositório institucional ARCA Dspace;

- Banco de Recursos Audiovisuais em Saúde (BRAVS)

- Conformidade com as diretrizes da Política de Acesso

Aberto da Fiocruz.

Figura 1 - Diagrama dos fluxos de trabalho dos objetos digitais audiovisuais da VSD

Fonte: João Guilherme Nogueira Machado, Eliane Batista Pontes, Cleomar Huche Lopes (2019).

Os arquivos de vídeo advindos de cartões de memória e outros dispositivos, após passarem por verificação de vírus, são submetidos a um processamento técnico para arquivamento, que envolve a criação de SIPs. Esse processo se inicia pela nomeação dos arquivos, que em seguida são estruturados em dossiês em conformidade com uma estrutura de arranjo arquivístico previamente definida. O dossiê abriga duas pastas: 'Objects', onde são depositados os arquivos a serem preservados; e 'Metadata', contendo uma planilha de metadados. Aqui são utilizados diferentes tipos de metadados (descritivos, técnicos e de preservação), seguindo padrões específicos (como Dublin Core, PBCore, PREMIS e reVTMD), sendo que os metadados técnicos embutidos nos arquivos são extraídos por meio do MediaInfo, software gratuito e de código aberto. 
Em seguida, a fim de verificar a integridade e a fixidez dos objetos digitais, valores de checksum são gerados por meio do Md5Checker, igualmente gratuito e aberto. Os objetos digitais são, então, armazenados tanto em servidor local quanto em discos rígidos externos e fitas de dados do tipo LTO 6.

Após o processamento técnico, os materiais são revisados, pois devem estar em conformidade com a estrutura de SIPs para admissão no Archivematica. O passo seguinte envolve a validação dos SIPs, que devem seguir as diretrizes estabelecidas pelo OAIS, para a posterior geração de AIPs, por meio do repositório digital.

Por fim, para a etapa de acesso são gerados arquivos destinados à visualização por meio da integração entre o Archivematica e o repositório institucional da Fiocruz/ARCA (que utiliza a plataforma DSpace). Também estão sendo realizados estudos de interoperabilidade entre o Archivematica e o Banco de Recursos Audiovisuais em Saúde (BRAVS), da própria VSD/Icict, enquanto opção adicional de plataforma de acesso.

\section{CONSIDERAÇÕES FINAIS}

O tema da preservação digital atualmente perpassa praticamente todas as instituições de guarda e os campos de conhecimento, tendo impactado profundamente a maneira pela qual os documentos são produzidos, gerenciados, salvaguardados e acessados. Este relato de experiência procura contribuir para esse cenário ao descrever os detalhes em torno da elaboração do Plano de Preservação Digital da VideoSaúde - Distribuidora da Fiocruz.

A elaboração do plano revelou a importância do documento tanto para lançar luz sobre o atual cenário da unidade (Icict) quanto para apontar para as ações necessárias à preservação digital do seu acervo audiovisual, de acordo com recomendações e padrões estabelecidos pelo campo. O documento reflete, de modo geral, a conscientização da VSD - e da Fiocruz, de maneira mais ampla - sobre a importância do desenvolvimento de estratégias de preservação digital do seu acervo.

Por meio do plano, a VSD teve como objetivo se aproximar da norma OAIS, incorporando o uso dos pacotes de informação, que deverão ser gerenciados por um repositório digital de código aberto (Archivematica). O conjunto de ações e procedimentos detalhados no plano visam também oferecer certo nível de presunção de autenticidade dos documentos digitais tratados, tanto pelo uso dos pacotes quanto por um conjunto de ferramentas dedicadas à preservação digital. Por meio de um fluxo de trabalho palpável, do uso de metadados consistentes e da aplicação de um conjunto de tecnologias e de ferramentas de código aberto, o plano procura, portanto, estar de acordo com as recomendações mais atualizadas do campo da preservação digital.

Submetido a uma política e eventualmente a um programa, um plano de preservação digital é um instrumento estratégico para apontar para ações práticas, executadas em curto prazo, sendo um documento essencial para qualquer atividade de preservação digital. Baseado em modelos utilizados por instituições de referência, o Plano de Preservação Digital da VSD pode vir a preencher uma lacuna de ausência de documentos dessa natureza por parte das instituições de guarda brasileiras, que não costumam ter como prática a formalização dos seus procedimentos de preservação digital.

\section{REFERÊNCIAS}

1. International Association of Sound and Audiovisual Archives. A Salvaguarda do Patrimônio Audiovisual: Ética, Princípios e Estratégia de Preservação (IASA-TC 03) [Internet]. 2017 [citado em 2020 maio 03]. Disponível em: https://www.iasaweb.org/sites/default/files/downloads/publications/TC03 4th edition Portuguese.pdf.

2. Edmondson R. Arquivística audiovisual: filosofia e princípios [Internet]. 2017 [citado em 2020 maio 01]. Disponível em: https://unesdoc.unesco.org/ark:/48223/pf0000259258.

3. Consultative Committee for Space Data System. Reference Model for an Open Archival Information System (OAIS). Magenta Book [Internet]. Washington, 2012 [citado em 2020 maio 03]. Disponível em: http://public.ccsds.org/publications/archive/650x0m2.pdf. 
4. Thomaz KP, Soares AJ. A preservação digital e o modelo de referência Open Archival Information System (OAIS). DataGramaZero [Internet]. 2004 [citado em 2020 abr 20];5(1). Disponível em: http://hdl. handle.net/20.500.11959/brapci/6608.

5. Conselho Nacional De Arquivos (BR). Câmara Técnica de documentos eletrônicos. Diretrizes para a implementação de repositórios arquivísticos digitais confiáveis - RDC-Arq. Rio de Janeiro: Arquivo Nacional, 2015. [citado em 2020 abr 30]. Disponível em: http://www.conarq.gov.br/images/publicacoes textos/diretrizes rdc arq.pdf.

6. International Organization for Standardization. ISO 16363:2012 - Audit and certification of trustworthy digital repositories [Internet]. 2012 [citado em 2020 maio 03]. Disponível em: https://www.iso.org/ standard/56510.html.

7. National Digital Information Infrastructure and Preservation Program. Levels of Digital Preservation [Internet]. 2018 [citado em 2020 maio 03]. Disponível em: https://ndsa.org/publications/levels-ofdigital-preservation/.

8. Baggio CC, Flores D. Estratégias, critérios e políticas para preservação de documentos digitais em arquivos. Ciênc. Inf. [Internet]. 2012 [citado em 2020 abr 30];41(2/3). Disponível em: http://revista. ibict.br/ciinf/article/view/1336.

9. Silva Junior LP, Mota VG. Políticas de preservação digital no Brasil: características e implementações. Ciênc. Inf. [Internet]. 2012 ján,/abr. [citado em 2020 abr 30];41(1):51-64. jan./abr. 2012. Disponível em: http://revista.ibict.br/ciinf/article/view/1351/1530.

10. Arquivo Nacional (BR). Recomendações para elaboração de política de preservação digital [Internet]. 2019 [citado em 2020 abr 30]. Disponível em: http://arquivonacional.gov.br/images/ Politica presercacao digital.pdf.

11. Canadian Heritage Information Network. How to use the Digital Preservation Toolkit [Internet]. 2018 [citado em 2020 abr 30]. Disponível em: https://www.canada.ca/en/heritage-information-network/ services/digital-preservation/how-to-digital-preservation-toolkit.html.

12. Arellano MA. Preservação de documentos digitais. Ciênc. Inf. [Internet]. 2004 [citado em 2020 abr 30];33(2):15-27. Disponível em: http://www.scielo.br/scielo.php?script=sci arttext\&pid=S0100$19652004000200002 \& \operatorname{lng}=$ pt\&tlng=pt.

13. Sierman B, Jones C, Elstrøm G. SCAPE - Catalogue of preservation policy elements [Internet] 2014 [citado em 2020 abr 30]. Disponível em: http://www.scape-project.eu/wp-content/uploads/2014/02/ SCAPE D13.2 KB V1.0.pdf.

14. Hofman et al. Preservation plan template. The Planets project [Internet]. 2008 [citado em 2020 abr 30]. Disponível em: http://www.ifs.tuwien.ac.at/dp/plato/docs/plan-template.pdf.

15. Becker C, Kulovitz H, Guttenbrunner M, Strodl S, Rauber A, Hofman H. Systematic planning for digital preservation: evaluating potential strategies and building preservation plans. International Journal on Digital Libraries [Internet]. 2009 [citado em 2020 abr 30];10(4)133-157. Disponível em: http://www.ifs. tuwien.ac.at/ becker/pubs/becker-ijdl2009.pdf.

16. Canadian Heritage Information Network. Digital Preservation Plan Framework for Cultural Heritage Institutions [Internet]. 2017 [citado em 2020 abr 30]. Disponível em: https://www.canada.ca/en/ heritage-information-network/services/digital-preservation/plan-framework-museums.html\#a7.

17. The Royal College of Music Museum. Action Plan for Digital Preservation [Internet]. 2015 [citado em 2020 abr 30]. Disponível em: https://www.rcm.ac.uk/media/13.a.3\%20App3 Digital\%20preservation.pdf.

18. Wheaton College Library and Archives. Digital Preservation Plan [Internet]. 2019 [citado em 2020 maio 01]. Disponível em: https://library.wheaton.edu/sites/default/files/Digital Preservation Plan.pdf.

19. Digital Preservation Coalition. Digital Preservation Handbook [Internet]. 2015 [citado em 2020 abr 30]. Disponível em: https://www.dpconline.org/handbook.

20. Fundação Oswaldo Cruz (BR). Política de preservação dos acervos científicos e culturais da Fiocruz/ Fundação Oswaldo Cruz [Internet]. 2018 [citado em 2020 abr 30]. Disponível em: https://portal.fiocruz. br/documento/politica-de-preservacao-dos-acervos-cientificos-e-culturais-da-fiocruz.

21. Fundação Oswaldo Cruz (BR). Política de acesso aberto ao conhecimento [Internet]. 2014 [citado em 2020 abr 30]. Disponível em: https://portal.fiocruz.br/sites/portal.fiocruz.br/files/documentos/ portaria - politica de acesso aberto ao conhecimento na fiocruz.pdf. 
22. Fundação Oswaldo Cruz (BR). Política de comunicação da Fiocruz/ Fundação Oswaldo Cruz [Internet]. 2017 [citado em 2020 maio 01]. Disponível em: https://portal.fiocruz.br/sites/portal. fiocruz.br/files/ documentos/politica de comicacao da fiocruz.pdf.

23. Souza JF, Soares MA, Fernandes JN, Melo JH. Manutenção da cadeia de custódia: proposta de implantação e uso de softwares para gestão de documentos digitais na Fundação Cidade Viva [Internet]. In: $8^{\circ}$ Seminário de Saberes Arquivísticos; João Pessoa; 2017. [citado em 2020 abr 30];João Pessoa: UFPB, 2017. Disponível em: http://www.ufpb.br/evento/index.php/viii/ sesa/paper/viewFile/4585/2795.

24. Santos HM, Flores D. Introdução aos conceitos básicos do modelo Open Archival Information System no contexto da arquivística. Acervo [Internet]. 2019 [citado em 2019 mar 20];32(1):8-26. Disponível em: http://revista.arquivonacional.gov.br/index.php/revistaacervo/article/view/1029. 